\title{
BMJ Open A Community Jury on PSA screening: what do well-informed men want the government to do about prostate cancer screening - a qualitative analysis
}

\author{
Lucie Rychetnik, ${ }^{1,2}$ Jenny Doust, ${ }^{3}$ Rae Thomas, ${ }^{3}$ Robert Gardiner, ${ }^{4}$ \\ Geraldine MacKenzie, ${ }^{5}$ Paul Glasziou ${ }^{3}$
}

To cite: Rychetnik L, Doust J, Thomas R, et al. A Community Jury on PSA screening: what do wellinformed men want the government to do about prostate cancer screening-a qualitative analysis. BMJ Open 2014;4:e004682. doi:10.1136/bmjopen-2013004682

- Prepublication history for this paper is available online. To view these files please visit the journal online (http://dx.doi.org/10.1136/ bmjopen-2013-004682).

Received 13 December 2013 Revised 23 March 2014 Accepted 3 April 2014

CrossMark

For numbered affiliations see end of article.

Correspondence to Dr Lucie Rychetnik; lucie.rychetnik@nd.edu.au

\section{ABSTRACT}

Objective: Cancer screening policies and programmes should take account of public values and concerns. This study sought to determine the priorities, values and concerns of men who were 'fully informed' about the benefits and harms of prostate-specific antigen (PSA) screening; and empirically examine the value of a community jury in eliciting public values on PSA screening.

Setting: Community jury was convened on the Gold Coast, Queensland (Australia) to consider PSA screening benefits and harms, and whether government campaigns on PSA screening should be conducted.

Participants: 27 men (volunteers) aged 50-70 with no personal history of prostate cancer and willing to attend jury 6-7 April 2013: 12 were randomly allocated to jury (11 attended).

Outcome measures: A qualitative analysis was conducted of the jury deliberations (audio-recorded and transcribed) to elicit the jury's views and recommendations. A survey determined the impact of the jury process on participants' individual testing decisions compared with control group.

Results: The jury concluded governments should not invest in programmes focused on PSA screening directed at the public because the PSA test did not offer sufficient reassurance or benefit and could raise unnecessary alarm. It recommended an alternative programme to support general practitioners to provide patients with better quality and more consistent information about PSA screening. After the jury, participants were less likely to be tested in the future compared with the controls, but around half said they would still consider doing so.

Conclusions: The jury's unanimous verdict about government programmes was notable in the light of their divergent views on whether or not they would be screened themselves in the future. Community juries provide valuable insights into the priorities and concerns of men weighing up the benefits and harms of PSA screening. It will be important to assess the degree to which the findings are generalisable to other settings.

\section{Strengths and limitations of this study}

- First published study of a community jury on the topic of prostate-specific antigen (PSA) screening.

- Provides in-depth analysis of informed men's priorities and values regarding PSA testing.

- Establishes the value of the community jury as a deliberative method for engaging the public in debates about cancer screening to elicit their informed views on policy questions.

- The broader generalisability of the views and conclusions of this jury has not yet been tested.

\section{INTRODUCTION}

The benefits and harms of prostate-specific antigen (PSA) screening have been debated for several decades. Based on current evidence, it is possible that screening improves survival but also leads to harms, particularly the diagnosis and treatment of cancers that would not otherwise become clinically apparent. ${ }^{1-3}$ It was hoped that two large randomised controlled mass population trials with survival as the primary end-point would provide a conclusive answer to the benefits and harms of screening, but the US PLCO trial found no benefit, ${ }^{4}$ possibly because a large proportion of men in the control arm were screened and the European ERSPC trial showed a small reduction in prostate cancer mortality (1 life saved for every 1055 men screened) though no reduction in allcause mortality. ${ }^{5}$

This equivocal evidence has led to disparate recommendations about PSA screening. The National Screening Committee in the UK and the US Preventative Task Force have advised against routine PSA testing for asymptomatic men. ${ }^{6}{ }^{7}$ The American Urological Association recommends routine PSA screening for men between the ages of 
55 and 69. ${ }^{9}$ The 2013 Prostate World Congress Melbourne Consensus Statement on Prostate Cancer Testing did not recommend routine screening, but recommended that well-informed healthy men aged 50-69 be counselled about the positive and negative aspects of PSA testing and the ability of PSA testing 'to reduce their risk of metastases and prostate cancer-specific mortality'. ${ }^{10}$

Owing to increasing recognition of the potential harms from screening, information about screening programmes has shifted from emphasising screening uptake to ensuring potential participants are provided with adequate information to make an informed choice about whether or not to be screened. ${ }^{11-13}$ This, however, requires understanding of complex issues, such as disease-specific mortality, avoidance of metastatic disease and latent cancers that are indolent in nature. The complexity is further compounded by the uncertainties regarding the estimates of screening outcomes. Moreover, the concept of potential harm from an early detection of cancer runs counter to messages men may have previously heard regarding the benefits of early detection. Men with a family history of prostate cancer are particularly likely to have concerns about the benefits and harms from screening.

While offering evidence-based information is ethically imperative, ${ }^{14}$ the complexities of PSA screening make this difficult to achieve within the context of the average clinical consultation and can be burdensome for patients and clinicians. ${ }^{15}$ Indeed some patients prefer to be advised what to do rather than considering detailed information about benefits and harms. ${ }^{11} 16$ All recommendations on PSA testing emphasise the provision of information and shared decision-making. We conducted a community jury process ${ }^{17-19}$ to determine the priorities, values and concerns regarding PSA screening among men aged 50-70 who we 'fully informed' about the reasons for and against screening. The jury members were asked to deliberate evidence presented by experts on PSA screening and invited to formulate recommendations on potential government actions. A survey using a randomised control design was incorporated to also determine the impact of the jury process on participants' knowledge and individual testing intentions (personal communication, Thomas R, Glasziou P, Rychetnik L, et al, 2013). The protocol was registered with the Australian and New Zealand Clinical Trials Registry (ACTRN12612001079831).

\section{METHOD}

Community juries provide an opportunity to examine what 'mini-publics' would conclude if well-informed and supported to deliberate on a given topic. ${ }^{20}$ While various kinds of deliberative methods exist, we adopted the community jury method as this has been successfully applied in other settings to consider questions on breast cancer screening. ${ }^{18} 19$

\section{Recruitment and selection}

The study participants were recruited through unpaid news articles, one paid advertisement in a local paper, two radio interviews and two presentations by the jury facilitator (RT) at Rotary Club community groups. Men were eligible to participate in the study if they were aged between 50 and 70, had no personal history of prostate cancer and were willing to attend an information session on Friday night and community jury sessions on Saturday and Sunday. We sought to recruit 12 participants to the jury: 31 men were recruited, 4 withdrew prior to the Friday information night, and all of those who attended the information session chose to participate in the study randomisation. The 27 participants attending the information session were randomly allocated to either the jury $(n=12)$ or a control group $(n=15)$ by selecting a folded piece of paper from a container. Members of both groups were provided with two fact sheets about PSA screening. ${ }^{21} 22$ The jury members were given additional summarised information to take home ${ }^{23-25}$ subsequently discussed as part of the jury process.

\section{Questions for deliberation by the community jury}

At the start of the community jury process, the participants were invited to consider two questions about potential government actions regarding PSA screening (box 1), with the aim of finalising a group response to these questions at the end of the second day. The terms government 'campaigns' and 'organised invitation programme' were purposefully left open so that the jury members could deliberate among themselves on what types of government action would or would not be appropriate. The second question about an invitation programme was asked because this had been identified by men's health advocacy groups as a way of matching breast cancer screening services offered to women.

\section{Community jury process}

The community jury was conducted on the 6-7 April 2013 at Bond University, Queensland, Australia. The jury process was informed by a previous jury conducted in 2007 to examine women's views on mammography screening (protocol details provided by the authors via personal communication) ${ }^{19}$ Day 1 focused on interrogating the expert evidence and day 2 on jury deliberations. On the first day of the PSA screening jury, the

Box 1 Questions posed to the jury about potential government action

Should government campaigns be provided (on prostatespecific antigen screening) and if so, what information should be included in those campaigns?

- What do you as a group of men think about a government organised invitation programme for testing for prostate cancer? 
participants heard presentations from the following experts:

Professor Jim Dickinson, University of Calgary (visiting scholar at Bond University at the time of the jury) who provided information about the prostate, prostate cancer and the methods used to diagnose and treat prostate cancer.

Professor Robert (Frank) Gardiner, Professor of Urology, University of Queensland who presented information in support of selective screening of informed men and additional information on prostate cancer diagnosis, prognosis and treatment (RG).

Professor Paul Glasziou, Director, Research Centre for Evidence-based Practice, Bond University who presented on why he did not recommend screening (PG).

The three expert sessions ran for approximately $40 \mathrm{~min}$ each, followed by questions from the jury. Each session was followed by a facilitated discussion to elicit the men's reflections and responses to the information presented. Any further questions arising from the facilitated discussions were noted and addressed on day 2. Expert witnesses RG and PG were introduced to the jury as members of the research team. Other than to present evidence and answer the jury's questions, the expert witnesses did not attend any of the jury deliberations.

At the start of day 2, the jury again reflected on the issues raised from day 1 and identified any final questions for the experts, which were answered via a speakerphone. The jury then deliberated without a facilitator present on the two questions about potential government action on PSA screening (box 1). Finally the jury's conclusions and recommendations were recorded in a facilitated (LR) feedback session at the end of day 2.

\section{Data collection and analysis}

The complete community jury process was audiorecorded and transcribed, including the experts' presentations and Q\&A sessions, all participant deliberations (facilitated and unfacilitated) and the final compilation of the jury's response and recommendations about government action on PSA screening. The jury's recommendations were compiled onto a flipchart and each point was reviewed and corrected as required by the participants to ensure that the summary of the jury's verdict accurately represented the group's deliberations and conclusions. In addition, two researchers (LR and GM) observed the jury process to compile field notes and provide feedback to the primary facilitator on group process and participant interactions.

The qualitative findings were derived from an analysis of the full transcripts of the jury process. The text was analysed in a multistage process comprising detailed descriptive and conceptual coding followed by the preparation of analytical synthesis memos ${ }^{26}$ on topics such as reasons for attending jury, important concerns about PSA testing, areas of consensus, areas of divergence and factors influencing personal decisions. Findings on the jury process were also derived from the transcripts, plus from the observational field notes and all researchers' reflections documented in postjury memos and email exchanges. The validity, relevance and interpretation of the findings were reviewed in research team discussions. The qualitative findings are summarised under 'reasons for attending the jury', 'core values related to PSA screening' and boxes 2-4. The jury's recommendations and rationale for their final verdict are summarised in the section 'community jury verdict on community-level questions'.

The jury participants completed two written surveys; one before the jury (Friday evening) and one immediately after the jury (Sunday lunchtime). The control group also completed the first survey on Friday and the second one by mail. The first survey collected demographic data and included questions on previous PSA tests and intention of getting tested for prostate cancer in the future if they had no symptoms (scale 0 'not at all' to 10 'absolutely'). It also included questions on sources of information about prostate cancer testing (checklist of options) and how informed the men perceived themselves to be about the benefits and harms of prostate cancer testing (scale 0 'not at all' to 4 'very'). The second survey re-examined the men's perceptions of how informed they considered themselves and their intention of having PSA screening in the future if they had no symptoms (analysed by linear regression ${ }^{27}$ and repeated measures analysis of variance).

\section{RESULTS}

\section{Description of study participants}

Of the 12 men randomised to the community jury, 1 withdrew prior to Saturday and another was unwell and did not return on Sunday. Thus 11 men contributed to the discussions on day 1 , and 10 men contributed to the

Box 2 Information identified by the men as important but unexpected or surprising

Prevalence of prostate cancer among older men (higher than expected).

- Progression of many prostate cancers (slower than expected).

- That prostate cancers may not have any clinical/health implications (unexpected).

- Scale of prostate-specific antigen (PSA) test levels and thus what it means to have 'raised' PSA levels (scale greater than expected).

- Degree of uncertainty about correlations between PSA test results and risk of cancer (higher than expected, some unaware of benign hyperplasia or other causes of raised PSA levels).

- Treatment side-effects such as impotence and incontinence (higher than expected).

- Notion of PSA testing as a matter of individual choice, rather than indicated by evidence or the 'right' thing to do (unexpected). 


\section{Box 3 Points of general consensus}

In general the men on the jury agreed on the following issues and points:

- Need for better and more standardised information; particularly more about the limitations, pros and cons of prostatespecific antigen (PSA) testing. The group particularly liked a figure based on available trial data that reported the number of men harmed (side-effects of treatment and associated psychological effects) and the 1 potential life saved per 1000 men screened.

- Need for general practitioners (GPs) to advise men of why PSA testing is not recommended by their guidelines.

- Importance of men taking responsibility and being able to make their own informed personal decisions about testing.

- Need for GPs to provide information about what it means to have a raised PSA test: 'if she'd talked to me just briefly about these things in terms of the imprecise nature of the whole screening process, I would have been a lot better off and felt a lot less stressed on leaving that day.'

- Valuing the availability of the test for those who want it.

- Valuing the time to ask questions and discuss issues with experts.

- Obtaining information from an independent source, with no financial or other vested interests.

- Not promoting PSA testing to the general population given the current uncertain status of the evidence and likelihood of findings of latent cancers if you look for them.

- Avoiding unnecessary anxiety among their family, friends and the community associated with promoting PSA testing when considering the uncertainty of the PSA test and not knowing how to interpret the results.

- Directing funds from screening towards generating better diagnostic tests, predictors to distinguish aggressive versus indolent cancers and safer treatment options.

- Importance of not wasting government funds on doing wasteful testing, importance of considering costs and benefits of government-funded programmes, not focusing on something if it is not sufficiently important as a health concern or risk 'In most people it isn't an issue, why make it an issue'.

- Important to prioritise those things that are more likely to impact on men's health.

- Perception that government sponsored information sent directly to public is often thrown out or ignored (gave example of colorectal cancer screening material).

final jury verdict. All 11 participants completed the prejury and postjury questionnaire.

\section{Demographics, PSA screening information sources and prior testing}

The 11 jury participants were aged between 53 and 68 years (mean age $=61, \mathrm{SD}=5.04$ ). Two participants had postgraduate qualifications $(18 \%)$, three were university or technical college graduates $(27 \%)$, four had some university or technical college experience $(37 \%)$ and two had a high school education or less (18\%). Prior to the jury, the men reported obtaining information from a variety of sources; general practitioners (GPs) were the mostly common source of information (nominated by 8

\section{Box 4 Some differences of opinion}

The men on the jury expressed some differences of opinion on the following points:

- Personal decisions on whether or not it is better to have the test

'..is there a test for lung cancer, heart disease, colon cancer, dementia, diabetes? l'd be getting tested for all those long before l'd get a bloody prostate test'.

- The importance of impotence and incontinence against the risk of death

P1 'I would have thought longevity at 70 was more important than sexual activity.'

$P 2$ 'Oh it depends'

P3 'Probably a lot of men..'

P2 'Horses for courses, I think'

P1 'I'm just saying, who would die over sex?'

- Whether or not (degree to which) men in general will want all of the information provided to the community jury-but group agreed the information should be available for those who do want it

- Whether or not they want doctors to advise/tell them what to do, or whether it is up to each man to make their own decision

- Whether or not it had been a good idea for them to ask the expert presenters what their personal decisions were about prostate-specific antigen (PSA) testing. Most said they wanted to know, one man said the responses swayed his own view too much and he would have preferred not to know (The group asked the presenters whether or not they had had a PSA test: one had, two had not)

men), followed by family and friends (nominated by 5 ), the Internet and media (nominated by 4 men each; table 1). Ten men on the jury reported having previously had a blood test for prostate cancer. Of these, 2 had been tested once (18\%), 3 had been tested twice (27\%), the remaining 5 had each been tested on $3,6,7,8$ and 12 occasions, respectively ( $9 \%$ each).

\section{Reasons for attending the jury}

The men said they agreed to participate primarily to learn more about prostate cancer and PSA testing. Several noted they wanted to become more aware and informed about their health, that men generally were

Table 1 Reported sources of information on testing for prostate cancer prior to jury

\begin{tabular}{lll}
\hline & N=11 & Per cent \\
\hline General practitioner & 8 & 73 \\
Family and friends & 5 & 46 \\
Internet & 4 & 36 \\
The media & 4 & 36 \\
Other (urologist/surgeon) & 2 & 18 \\
Other (hospital seminar) & 1 & 9 \\
Never looked for information & 2 & 18 \\
\hline NB: Men could endorse more than one category.
\end{tabular}

NB: Men could endorse more than one category. 
not very good at this, and they had decided to change their previous 'she'll be right' attitude. 'I guess having reached the age of 60 , realising that we're not all bulletproof...' Group discussions also identified the role of wives and doctors in encouraging a more preventive approach to healthcare. A majority of the men said the jury was an opportunity to learn about a topic on which they knew very little, heard conflicting messages and reports on what to do or had 'snippets of information each way' for and against testing. One man revealed he was undergoing regular monitoring of his PSA levels by an urologist after his first PSA test had been ordered by a GP without his knowledge when he had attended for a cholesterol check. One other man said he had prior urological symptoms but had been cleared of significant disease. Several participants reported the experiences of family and/or friends with prostate cancer that resulted in variable outcomes, including a number of premature deaths.

\section{Core values related to PSA screening}

The men discussed their own and others' experiences of PSA testing and compared the evidence presented at the jury to the information and advice they received from GPs and other doctors. In their reflections, they particularly noted how much of the evidence presented by the experts was unfamiliar and surprising for them; particularly the likelihood of a raised PSA result, the uncertainty about what raised PSA levels mean, and the high prevalence of prostate cancer with no clinical significance. The issues that men identified as important information but unexpected or surprising are summarised in box 2 .

Overall the group concluded that given the uncertain evidence and divergent opinions about screening, PSA testing was an individual choice for which they needed to take personal responsibility. For some in the group, the idea that it was acceptable to chose not to have a PSA test-even if offered or advised to have one-was a revelation as they had previously interpreted such a choice as avoidance or as being 'slack' about their health:

I was of the opinion when I came in that every man over 60 should be screened as a matter of fact, but now I think I've changed my ideas, that it's a personal decision

The group also concluded that the poor quality or lack of information provided by GPs did not currently support men in making informed decisions. Thus one of the most discussed concerns among the participants was the variable and inconsistent advice provided by their GPs; as well as the inadequate or conflicting information and messages about PSA testing from different doctors, media campaigns and other sources. The points reflecting general group consensus during deliberations are summarised in box 3, while some differences in opinion are summarised in box 4 .

The men were generally concerned that GPs were not following the guidelines of their College, ${ }^{24}$ and that it depended on which GP they went to as to whether or not they were advised to have a PSA test, and what (if any) information was provided when a test was ordered. For example, the jury shared experiences of their doctors requesting PSA tests without informing the patient, for example at a time when another blood test was also requested. For one participant this experience resulted in significant personal regret and ongoing anxiety associated with continued monitoring 'If only I hadn't gone for the cholesterol test in 2007'. Conversely, another man had been refused a PSA test even though he specifically asked for it and he changed his doctor as a result. The group also shared their own and others' experiences of inconsistency in how different doctors interpret PSA test results (eg, what degree of elevated PSA levels were perceived to be ok or expected); and how urologists varied in what they recommended once PSA levels were found to be raised (eg, biopsy vs no biopsy, surgery or monitoring). The men also worried about the lack of standardisation of testing procedures, for example, whether or not men were advised to abstain from sexual activity before testing.

In addition to the core concerns about the available information and advice, the men were also concerned about the relationship between PSA testing and anxiety and depression. On deliberating the evidence many concluded that the apparent uncertainties in the science of PSA testing primarily mean that a raised PSA test result (or subsequent diagnosis of prostate cancer) was a source of significant anxiety without offering any valuable information on how to act: All they're going to say is yeah, you've got it. You're going
to worry for the next 15 years, is it bigger, is it smaller,
am I going to get tested again?

After deliberating the evidence most of the jury concluded that having a PSA test was a genuinely difficult and personal choice. As a result, several of the men expressed concerns about the active promotion of PSA testing by some doctors and through public campaigns and charities such as 'Movember'. ${ }^{28}$ This was considered by some to be deceptive in the light of current uncertainty about what PSA results mean, the lack of available technologies to differentiate aggressive versus indolent cancers and the lack of satisfactory/safe treatment options for prostate cancer. The jury's discussions focused on the importance of not harming men through unnecessary investigations and treatments, including those for whom the cancer will never progress, or for whom other conditions would kill them first. Several in the group agreed that for many of their peers other emerging health problems, including 
cardiovascular disease, diabetes or mental health were more important concerns than prostate cancer.

\section{Community jury verdict on community-level questions}

The jury's responses to the community-level questions (box 1) on potential government action on PSA screening for prostate cancer were as follows (final day, $n=10$ ):

Recommended against any government campaigns aimed at the public on the topic of PSA screening. This included a recommendation against any organised invitation programme for prostate cancer screening (unanimous).

Proposed instead a campaign targeting GPs to assist GPs to provide better quality and more consistent information to their patients about PSA testing for prostate cancer. The men particularly wanted GPs to provide to patients information on: the unreliable nature of the PSA test, prevalence of raised PSA levels in older men, prevalence of prostate cancer relative to risk of death, screening outcomes (rates/1000 men screened), treatment side-effects (rates; unanimous).

Proposed that facts about PSA screening for prostate cancer, including that it is not currently recommended in Australian GP practice guidelines and an explanation of why, could be provided directly to the public if it was included as part of a broader 'men's health' information programme or website. The latter was preferred to identifying PSA screening as a targeted priority issue (unanimous).

\section{Jury's rationale for final verdict}

The jury's primary concern was that any public campaign focused on PSA testing for prostate cancer had potential to cause anxiety and alarm among the majority of men who did not need to be concerned about prostate cancer. Other reasons given by the jury for why they believed a government campaign on PSA screening was not warranted were nominated as follows:

- Contradictory nature of the current status of the science;

- Unreliable nature of the PSA test;

- Low incidence of mortality from prostate cancer;

- High cost of such a campaign;

- Funds required are more likely to be better used on research into the diagnosis and treatment of prostate cancer.
'We don't want the government to invite us or our mates to come along and get tested. We don't want that to happen because we don't want our mates to worry. We don't want people to make a fuss, we don't want our government to waste our money.'

\section{Individual-level PSA testing decisions}

After the jury the men considered themselves better informed about the benefits and harms of prostate cancer testing compared with prior to the jury ( $\mathrm{F}=14.34$, $\mathrm{p}=0.004$; table 2 ). This improvement was significantly greater than in the control group $(\mathrm{F}=7.3, \mathrm{p}=0.01)$. Following the jury, the men also decreased their intention to be screened for prostate cancer in future compared with their intentions prior to the jury $(\mathrm{F}=8.83$, $\mathrm{p}=0.014$; table 2 ). The jury also scored 4.3 points lower on the postjury intention to test scale than the controls ( $p=0.001$; table 3 ). At the end of the jury, five men reported they were 'not at all' likely to get tested in the future if they had no symptoms, whereas six would consider it-and of these, four were more likely than not to do so (ie, scored $\geq 5$ on scale $0-10$; table 4 ).

\section{DISCUSSION}

Government policies must take account of public values and concerns. Deliberative methods such as community juries are well suited to support evidence-informed public engagement on screening policies and programmes. ${ }^{17}$ In this study, a group of men aged between 50 and 70, after deliberating on the benefits and harms of PSA screening, concluded that governments should not invest in any organised programmes focused on PSA screening that were directed at the public. They determined that the PSA test did not offer sufficient reassurance or benefit to warrant a public campaign, and that such an approach would raise unnecessary alarm about prostate cancer. The jury did however want men to continue to have access to the test and to be able to make an informed choice about whether or not to be screened. They recommended an alternative government programme aimed at supporting GPs to provide patients with better quality and more consistent information about the benefits and harms of PSA screening.

The jury's verdict on public campaigns was not anticipated by the research team; rather we expected that if anything, the jury may identify a need for a public education campaign on PSA screening. The jury

Table 2 Reported changes compare pre-post jury measures: perception of how well informed and how likely to test for prostate cancer

\begin{tabular}{|c|c|c|c|c|c|c|}
\hline \multicolumn{7}{|c|}{ Comparison of continuous variables at preassessment and postassessment $(\mathrm{N}=11)$} \\
\hline & \multicolumn{2}{|c|}{ Preassessment } & \multicolumn{2}{|c|}{ Postassessment } & \multirow[b]{2}{*}{$\mathbf{F}$} & \multirow[b]{2}{*}{ p Value } \\
\hline & $\overline{\text { Mean }}$ & $\overline{S D}$ & $\overline{\text { Mean }}$ & $\overline{S D}$ & & \\
\hline Informed about harms and benefits & 2.0 & 1.2 & 3.6 & 0.5 & 14.34 & 0.004 \\
\hline Likely to test for prostate cancer & 7.3 & 3.5 & 3.5 & 4.1 & 8.83 & 0.014 \\
\hline
\end{tabular}


Table 3 Future intention to test for prostate cancer comparing jury to controls

\section{Predicting future intention to test for prostate cancer ${ }^{\star}$}

\begin{tabular}{|c|c|c|c|c|c|}
\hline & B & SE B & Cl lower & Cl upper & p Value \\
\hline Constant & -0.11 & 1.51 & -3.25 & 3.03 & 0.944 \\
\hline Preassessment intention to test score & 0.72 & 0.16 & 0.38 & 1.06 & 0.000 \\
\hline How many times tested previously & 0.66 & 0.19 & 0.26 & 1.06 & 0.003 \\
\hline Group membership (jury/control) & -4.31 & 1.09 & -6.58 & -2.04 & 0.001 \\
\hline
\end{tabular}

Note. $\mathrm{N}=25$.

${ }^{*}$ As it was anticipated that men who had been tested for prostate cancer previously would be more likely to continue with this course of action, group differences in intention to be tested for prostate cancer in the future were examined using linear regression, adjusting for baseline future intention to test, the number of times a man had a prostate-specific antigen test at baseline, and his group membership.

overwhelmingly reported being previously unaware of the relative benefits and harms of screening, and their preference for obtaining such information from their doctor. The option of a government programme targeting GPs was nominated by the jury themselves, reflecting their primary concern about the lack of information provided by their doctors and their shared experiences of inconsistent PSA screening advice. The findings indicate the facilitation process had been open and non-directive.

Community juries are not intended to be representative of the wider population in the statistical sense; rather they offer valuable insights on the informed views and conclusions of a 'mini-public'. ${ }^{20}$ This study provides valuable insights into the concerns and priorities with regard to PSA testing among men aged 50-70; both as individuals interested in PSA testing, and as citizens invited to weigh community benefits and harms. The jury's unanimous verdict about government programmes was notable in the light of the men's divergent views on whether or not they would get tested again in future themselves if they had no symptoms. These findings support other literature indicating community juries delineate and rise above individual decisions to consider higher order questions about the common good. ${ }^{29}$ While the men's personal interest in PSA testing did not appear to hinder their willingness and ability to consider more broadly its relative value for their community, other kinds of public may have reached different conclusions. For example, a majority of the jury had been previously tested, and while the proportion of Australian men who have ever had a PSA test is unknown, approximately $20 \%$ of Australian men aged 45-74 years had

Table 4 Intention to be screened in future after jury process

\begin{tabular}{lcc}
\hline $\begin{array}{l}\text { Value: how likely to be tested if } \\
\text { no symptoms (0='not at all'; }\end{array}$ & Per \\
5='maybe'; 10='absolutely') & Frequency & cent \\
\hline 0 & 5 & 46 \\
4 & 2 & 18 \\
5 & 1 & 9 \\
8 & 1 & 9 \\
10 & 2 & 18 \\
Total & 11 & 100 \\
\hline
\end{tabular}

screening PSA tests between 2010 and 2011. ${ }^{30}$ In other countries such as the USA the participation in PSA testing is relatively high; around $50 \%$ among men aged $60-74 .^{31}$ The impact of these differences on the deliberation and conclusions of a jury on PSA testing is currently unknown.

It will be important therefore to repeat the deliberative process with other juries, both to examine the views of different publics, and to assess the generalisability of the findings to other parts of Australia and other countries with different information and services. Similarly, it will be relevant to assess the potential impact on jury deliberations or conclusions of varying aspects of the community jury process, such as the method of recruiting participants or of presenting evidence. Different publics could include men of different ages, a mixed group of men aged 50-70 and partners or other family members (particularly as the men noted the influence of partners on their health behaviours) or a random sample from the electoral roll-although these methods are still affected by respondents' level of interest. Other forms of evidence could include the personal stories of men affected by prostate cancer and/or the side-effects of treatment, or those without a diagnosis but whose PSA level is being monitored. Finally, it will also be valuable to compare the effectiveness of eliciting public values about cancer screening using other deliberative methods. $^{32}$

The recent Australian NHMRG Information for Health Practitioners: Prostate Specific Antigen (PSA) Testing for Prostate Cancer in Asymptomatic Men ${ }^{33}$ provides guidance on communicating the evidence on the benefits and harms of PSA screening to asymptomatic men. It will be imperative to identify effective mechanisms to facilitate implementation of this guidance within Australian general practice. It will be also important to better align and even regulate the messages about PSA testing that are promoted in media campaigns by prostate cancer charities and other non-government organisations and special interest groups so that more consistent information and advice is presented.

\section{Author affiliations}

${ }^{1}$ School of Medicine Sydney, University of Notre Dame Australia, Sydney, New South Wales, Australia 
${ }^{2}$ School of Public Health, University of Sydney, Sydney, New South Wales, Australia

${ }^{3}$ Centre for Research in Evidence-Based Practice (CREBP), Faculty of Health Sciences and Medicine, Bond University, Gold Coast, Queensland, Australia ${ }^{4}$ Centre for Clinical Research, University of Queensland, and Department of Urology, Royal Brisbane \& Women's Hospital, Queensland, Australia ${ }^{5}$ Faculty of Law, Bond University, Gold Coast, Queensland, Australia

Contributors LR led the preparation and subsequent revisions of the manuscript, contributed to the study design, and led the analysis and interpretation of the qualitative data. JD and PG led the conception and design of the study, contributed to the interpretation of the data and made substantial revisions to the manuscript. RT contributed to the study design, led the analysis and interpretation of the quantitative data, and made substantial revisions to the manuscript. RG and GM contributed to the study design and interpretation of the data, and made significant revisions to the manuscript.

Funding This work was supported by a Screening and Test Evaluation Program (STEP) grant (\#633033) from the National Health and Medical Research Council (NHMRC), a NHMRC Project Grant (\#1023791) and the Bond University Vice Chancellor's Research Grant Scheme.

Competing interests None.

Ethics approval The research project was approved by the Bond University Human Research Ethics Committee (R01570).

Provenance and peer review Not commissioned; externally peer reviewed.

Data sharing statement In addition to the qualitative analysis reported in this paper, a survey using a randomised control design was incorporated to determine the impact of the jury process on participants' knowledge and individual testing intentions. This paper includes the prejury and immediate postjury findings on the men's self-reported knowledge of PSA testing and future intentions to screen. Additional quantitative findings from this survey and the results of a 3-month follow-up measuring knowledge of PSA testing and intention to screen in future have been reported elsewhere (under review) and cited as reference 20 .

Open Access This is an Open Access article distributed in accordance with the Creative Commons Attribution Non Commercial (CC BY-NC 3.0) license, which permits others to distribute, remix, adapt, build upon this work noncommercially, and license their derivative works on different terms, provided the original work is properly cited and the use is non-commercial. See: http:// creativecommons.org/licenses/by-nc/3.0/

\section{REFERENCES}

1. Chou R, Croswell JM, Dana T, et al. Screening for prostate cancer: a review of the evidence for the U.S. Preventive Services Task Force. Ann Intern Med 2011;155:762-71.

2. Djulbegovic M, Beyth RJ, Neuberger MM, et al. Screening for prostate cancer: systematic review and meta-analysis of randomised controlled trials. BMJ 2010;341:c4543.

3. Ilic D, Neuberger MM, Djulbegovic M, et al. Screening for prostate cancer. Cochrane Database Syst Rev 2013;1:CD004720.

4. Andriole GL, Crawford ED, Grubb RL 3rd, et al. Prostate cancer screening in the randomized prostate, lung, colorectal, and ovarian cancer screening trial: mortality results after 13 years of follow-up. J Natl Cancer Inst 2012;104:125-32.

5. Schröder FH, Hugosson J, Roobol MJ, et al. Prostate-cancer mortality at 11 years of follow-up. $N$ Engl $\mathrm{J}$ Med 2012;366:981-90

6. Mackie A; UK National Screening Committee. Screening for prostate cancer review against programme appraisal criteria for the UK National Screening Committee (UK NSC). London: National Health Service, 2010.

7. Moyer VA. Screening for prostate cancer: U.S. Preventive Services Task Force Recommendation Statement. Ann Intern Med 2012;157:120-34.
8. American Urological Association. Early detection of prostate cancer: AUA guideline. 2013; (7 Jun 2013). http://www.auanet.org/education/ guidelines/prostate-cancer-detection.cfm

9. Mitka M. Group now advises against routine PSA screening. JAMA 2013;309:2316.

10. The Melbourne Consensus Statement on Prostate Cancer Testing. A consensus view on the early detection of prostate cancer, led by experts at the Prostate Cancer World Congress, Melbourne, 7-10 August 2013. http://www.prostatecancerresearch.org.au/new-apcr/ wp-content/uploads/

The-Melbourne-Consensus-Statement-on-PSA-Testing.pdf

11. Entwistle VA, Carter SM, Trevena L, et al. Communicating about screening. BMJ 2008;337:3.

12. Irwig L, Glasziou P. Informed consent for screening by community sampling. Effect Clin Pract 2000;3:47-50.

13. Stefanek ME. Uninformed compliance or informed choice? A needed shift in our approach to cancer screening. J Natl Cancer Inst 2011;103:1821-6.

14. Shaw D, Elger B. Evidence-based persuasion: an ethical imperative. JAMA 2013;309:1689-90.

15. Woolf $\mathrm{SH}$, Krist $\mathrm{A}$. The liability of giving patients a choice: shared decision making and prostate cancer. Am Fam Physician 2005;71:1871-2.

16. Levinson W, Kao A, Kuby A, et al. Not all patients want to participate in decision making - a national study of public preferences. J Gen Intern Med 2005;20:531-5.

17. Rychetnik L, Carter SM, Abelson J, et al. Enhancing citizen engagement in cancer screening through deliberative democracy. J Natl Cancer Inst 2013;105:380-6.

18. Hawkes N. Women 'jurors' are asked how to present risk-benefit ratio of breast cancer screening. BMJ (Clin Res Ed) 2012;345:e7886.

19. Paul $C$, Nicholls $R$, Priest $P$, et al. Making policy decisions about population screening for breast cancer: the role of citizens' deliberation. Health Policy 2008;85:314-20.

20. Goodin RE, Dryzek JS. Deliberative impacts: the macro-political uptake of mini-publics. Politics Soc 2006;34:219-44.

21. Andrology Australia. Factsheet: PSA testing. Victoria, Australia: Monash Institute of Medical Research, 2013. https://www. andrologyaustralia.org/wp-content/uploads/Factsheet_PSA-Test.pdf

22. Cancer Council Australia. Early detection factsheets: prostate cancer. 2013. http://www.cancer.org.au/about-cancer/ early-detection/early-detection-factsheets/prostate-cancer.html

23. Ilic D, Neuberger MM, Djulbegovic M, et al. Screening for prostate cancer (Review-Plain Language Summary). Cochrane Database Syst Rev 2013;1:CD004720.

24. Royal Australian College of General Practitioners. Guidelines for preventive activities in general practice (The Red Book) Chapter 98 (Prostate Cancer). 8th edn. South Melbourne, Victoria: The Royal Australian College of General Practitioners, 2012.

25. Urological Society of Australia and New Zealand. PSATesting Policy (executive summary). 2009. http://www.usanz.org.au/uploads/29168/ ufiles/USANZ_2009_PSA_Testing_Policy_Final1.pdf

26. Charmaz K. Constructing grounded theory: a practical guide through qualitative analysis. London: SAGE Publications, 2006.

27. Vickers AJ, Altman DG. Analysing controlled trials with baseline and follow up measurements. BMJ 2001;323:1123-4.

28. Movember Australia. About Movember. http://aumovembercom/ about/ (accessed 30 Jul 2013).

29. Elwood P, Longley M. My health: whose responsibility? A jury decides. J Epidemiol Community Health 2010;64:761-4.

30. Currow D, Armstrong B. PSA needs order MJA insight 2011; (25 May 2012). http://www.mjainsight.com.au/view? post=david-currow-bruce-armstrong-psa-needs-order\&post $\mathrm{id}=6489$ \& $\mathrm{cat}=\mathrm{comment}$

31. Prasad SM, Drazer MW, Huo D, et al. 2008 US preventive services task force recommendations and prostate cancer screening rates. JAMA 2012;307:1692-4.

32. Agency for Healthcare Research and Quality. The AHRQ community forum deliberative methods demonstration effective health care program. 2013. http://www.effectivehealthcare.ahrq.gov/ehc/assets/ File/Demonstration-Methods-Deliberative-130213.pdf

33. NHMRC. Public consultation on the draft Prostate Specific Antigen (PSA) testing for prostate cancer in asymptomatic men: information for health practitioners. 2013. http://consultations.nhmrc.gov.au/ public_consultations/prostate_cancer (accessed 31 Jul 2013). 